\title{
Timber Harvester Operator Killed Following a Chain Shot Incident
}
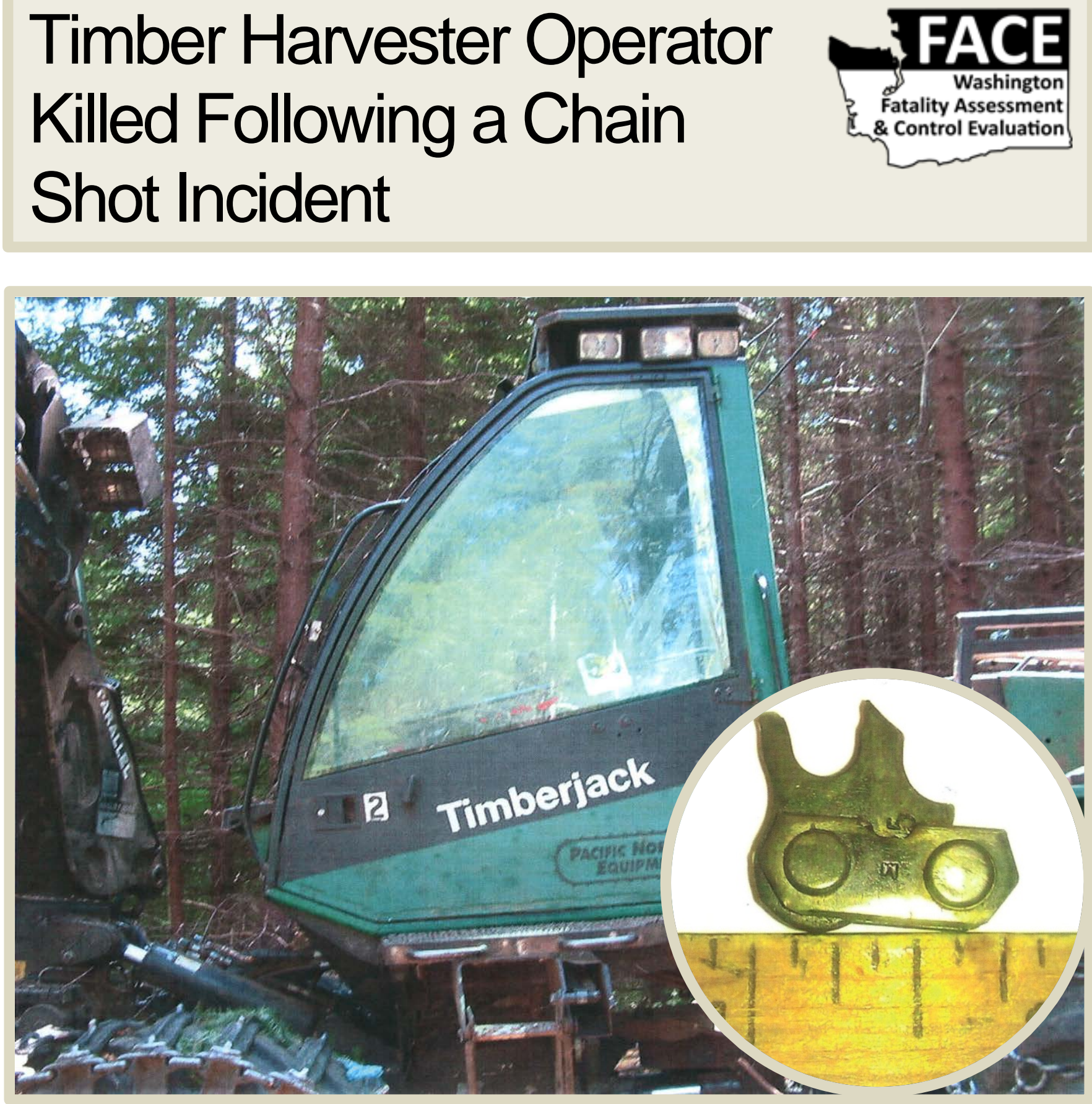

Investigation: \# 10WA04801

Release Date: 02-24-2014

SHARP Report: \# 52-30-2014 
TABLE OF CONTENTS

CONTENTS

PAGE

DEFINITIONS

3

SUMMARY

4

RECOMMENDATIONS

INTRODUCTION

EMPLOYER

EMPLOYER SAFETY TRAINING PROGRAM

TIMBER HARVESTER OPERATOR 6

CHAIN SHOT

HARVESTER

CUTTING CHAIN

INVESTIGATION

CONTRIBUTING FACTORS

CAUSE OF DEATH 13

RECOMMENDATIONS AND DISCUSSION 13

POST INCIDENT REMEDIATION

APPENDIX A 23

APPENDIX B $\quad 24$

ACKNOWLEDGEMENTS $\quad 26$

REFERENCES $\quad 26$

INVESTIGATOR INFORMATION $\quad 27$

FACE PRORGRAM INFORMATION 27 


\section{DEFINITIONS:}

$\begin{array}{ll}\text { APP } & \text { Accident Prevention Program } \\ \text { DNR } & \text { Department of Natural Resources } \\ \text { DOSH } & \text { Division of Occupational Safety and Health } \\ \text { ELZ } & \text { Equipment Limitation Zone } \\ \text { EMS } & \text { Emergency Medical Services } \\ \text { FACE } & \text { Fatality Assessment and Control Evaluation } \\ \text { FRI } & \text { Forestry Research Institute } \\ \text { HR } & \text { Human Resources } \\ \text { mm } & \text { Millimeters } \\ \text { NIOSH } & \text { National Institute for Occupational Safety and Health } \\ \text { OPS } & \text { Operator Protection Structure } \\ \text { PDS } & \text { Product Data Sheet } \\ \text { RPM } & \text { Revolutions per Minute } \\ \text { SHARP } & \text { Safety and Health Assessment and Research for Prevention } \\ \text { SMP } & \text { Svenska Mankinproving AB } \\ \text { SOPS } & \text { Standard Operating Procedures } \\ \text { WA } & \text { Washington State } \\ \text { WISHA } & \text { Washington Industrial Safety and Health Act }\end{array}$




\section{SUMMARY}

On August 12, 2010, a 47-year-old timber harvester operator (employed by a logging company) was fatally injured when he was struck in the neck by a broken saw chain link while processing a Douglas-fir tree and the cutting chain experienced chain shot. Chain shot is the high velocity separation and ejection of a piece or pieces of cutting chain from the end of a broken chain. ${ }^{[1]}$

The operator was using a Timberjack harvester equipped with a Timberjack cutting head to thin a stand of trees. Prior to the chain shot incident, the operator used the harvester to cut the Douglas-fir stem and move it to the left side of the operator's station for processing. When the operator started the cut-off saw to cut the tree into shorter lengths, the chain broke. It is believed by the employer and DOSH inspector, that when a portion of the broken chain hit a snow hole on the cutting head, chain shot occurred. Three pieces from the chain struck the operator's cab. One of the pieces penetrated the 12 millimeter (approximately $1 / 2$ inch) polycarbonate window made by Lexan and struck the operator in the neck. The injured operator contacted a co-worker in the area, who contacted emergency responders and the employer. The harvester operator was pronounced dead on the scene.

Most experts agree that the risk of chain shot cannot be completely eliminated. However, to prevent similar incidents the Washington State Fatality and Control Evaluation (FACE) team recommends several preventive measures that employers, harvester operators, employees on foot, and manufacturers can take to greatly reduce the risk.

Employers:

- Should create maintenance and guarding systems that reduce the chance of chain shot and protect workers.

- Train all workers who might encounter chain shot on standard operating procedures (SOPs) used for the prevention of chain shot.

Harvester operators:

- Should whenever possible avoid processing trees when the processing saw is in line with the operator's cab.

Workers:

- Should be aware of and in frequent communication with harvester operators regarding their proximity and alignment relative to timber harvesters and the location of safe zones.

Manufacturers:

- Should equip mechanized logging equipment with multiple safety systems to prevent chain shot and related injuries. 


\section{INTRODUCTION}

On August 12, 2010, the Washington State Fatality Assessment and Control Evaluation (FACE) program was notified by the Washington State Division of Occupational Safety and Health (DOSH) of the death of a 47-year-old timber harvester operator.

After reviewing the DOSH investigation report, Washington State FACE investigators interviewed the owner and human resources (HR) manager of the logging company. During the interview, the owner and HR manager provided information regarding the history, organization, and health and safety programs of the company, as well as insight into circumstances surrounding the incident. During the course of the investigation documents reviewed included police report, coroner's report, and DOSH investigation documents and photographs.

\section{Employer}

The employer has been in the logging business since the 1960s, and primarily cuts Douglas-fir, hemlock, and alder trees in Washington and Oregon. The employer started mechanized logging in the early 1990s. According to Washington State Department of Labor and Industries risk classification system, mechanized logging is defined as the entire process of felling, removal, yarding, processing, delimbing, bucking and loading of tree/logs by machine. ${ }^{[2]}$ The employer primarily does contract logging for companies that own large pieces of land intended for harvesting timber, such as tree farms. The employer contracts hand cutting and truck hauling duties.

At the time of the incident, the employer employed 110 fulltime employees, 5 of these employees had the same job duties and title as the operator.

\section{Employer Safety and Training Program}

The employer has monthly safety meetings, an annual safety meeting, and brief jobsite specific safety meetings daily. According to the DOSH inspection the employer has an appropriate Accident Prevention Plan (APP).

All new employees are required to participate in a New Hire Orientation training that lasts for about 2 hours. This training is conducted by the HR Manager with each individual employee. At the time of the incident, topics included in the New Hire Orientation training included: 
- Employer and employee responsibilities

- Safety and health training program

- General company policies and disciplinary policies

- Substance abuse policies
- Lockout/Tagout

- Hazardous materials protocols

- Working near power lines

- State laws relevant to their company in Washington and Oregon

The employer also has job-specific trainings. These job specific trainings cover topics relevant to the job the person would be completing, such as procedures for truck drivers and machinery operators working on a landing.

Machinery operators are required to show their ability to operate the machinery by reviewing training guides with a more experienced operator. The trainee must be able to show the more experienced operator that he or she understands how to safely operate the machine. According to the HR Manager, the training guides are reviewed on site (Appendix B). These forms are reviewed when employees are first hired and then annually after that. After reviewing the training guides, the new operator is observed by a more experienced operator employed by the logging company to ensure that they can operate the machine properly.

\section{Timber Harvester Operator (Victim)}

The operator had been working with this type of harvester as an operator since 1993 and had been a full-time employee since November 2008.

According to the employer, the operator was considered experienced with the Timberjack harvester, and provided training on how to operate the machine safely. When the operator was hired, the employer said that his training consisted of being observed for 1-2 days by another operator to ensure he followed the protocols used by the employer.

Prior to working for the logging company, the employee worked for similar companies doing the same work. He had received training from the harvester manufacturer on how to safely operate the harvester he was using at the time of the incident. The employer stated, that prior to working for the company, he and the operator had been at the same trainings and had informal discussions about the operation of harvesting equipment. The employer said that in these informal discussions that operator taught him more efficient ways to operate the harvesters. The employer also stated that the operator was very meticulous. For example, he maintained a log of the work he did, problems that arose while working, and the solutions he used to fix these problems. 
The operator's job duties included selecting the trees that needed to be cut, and operating and maintaining the harvester while in the field.

\section{Chain Shot}

Chain shot is the high velocity separation and ejection of a piece or pieces of cutting chain from the end of a broken chain. ${ }^{[1]}$. Chain shot occurs after the initial break and is often caused when the chain strikes something, such as the saw box, causing pieces from the chain to break loose. While chain shot can travel in any direction, the pieces of ejected chain usually travel along the plane of the saw bar. However chain shot can also spread out from the plane of the saw bar in a cone-like pattern. This is sometimes referred to the chain shot "cone zone" and starts at each end of the saw bar and increases in circular area away from the saw where chain shot is most likely to travel.

\begin{tabular}{|l|l|}
\hline Sequence of events & Diagrammatic representation \\
\hline After a chain break ..........
\end{tabular}

Figure 1: Diagram of chain shot from Oregon's The Mechanical Harvesting Handbook. (http://www.oregonproducts.com/pdf/harvester/MechanicalHarvesting 2005.pdf) 


\section{Harvester}

The machine involved in the incident was a 1996 Timberjack 1270B single grip harvester matched with a Timberjack $762 \mathrm{C}$ harvester cutting head (see photo 1 ). The harvester is designed to fell, limb, and cross-cut trees. The machine was purchased used, came with all service manuals, and the employer reviewed all maintenance records.

At the time of the incident the company was operating five harvesting machines. These five machines had a combined total of approximately 1 million hours of harvesting. This this was the first ever chain shot penetration of an operator cab window of a company owned harvester.

The cab window to the Timberjack harvester was made of $12 \mathrm{~mm}$ polycarbonate made by Lexan (see photo 2). The harvester cab window model was a Lexan Margard MR5E. According to the Product Data Sheet (PDS) the Lexan Margard MR5E has 250 times the impact strength of glass and 30 times that of acrylic.

The Lexan cab window is considered to be the protective equipment against chain shot by both the manufacturers of harvesters and those conducting mechanized logging. The employer had a similar harvester with $12 \mathrm{~mm}$ polycarbonate windows experience an incident of chain shot in which the chain did not penetrate the cab window. This confirmed the employer's belief that that the $12 \mathrm{~mm}$ Lexan cab window was sufficient protection for the operator.

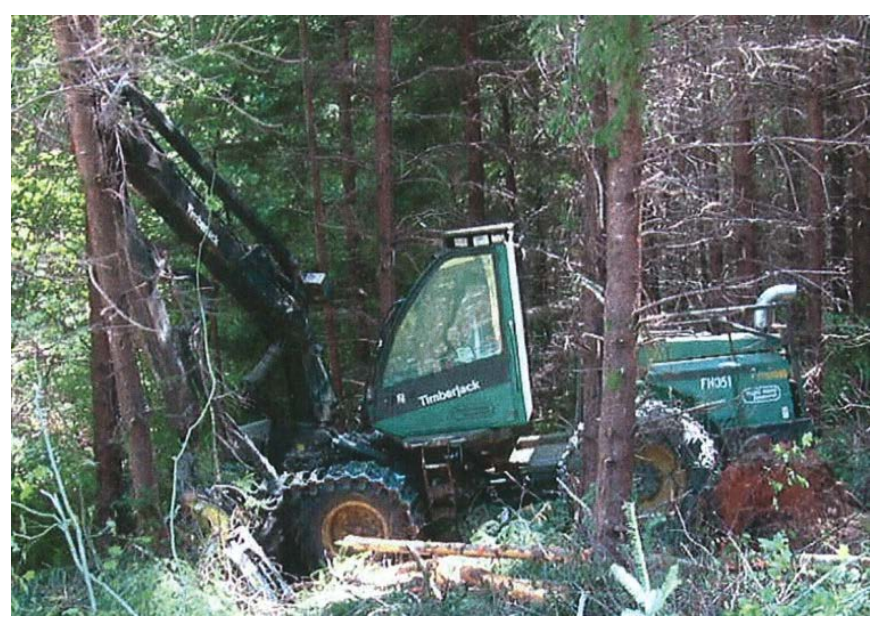

Photo 1: Timberjack 1270B harvester used by the operator.

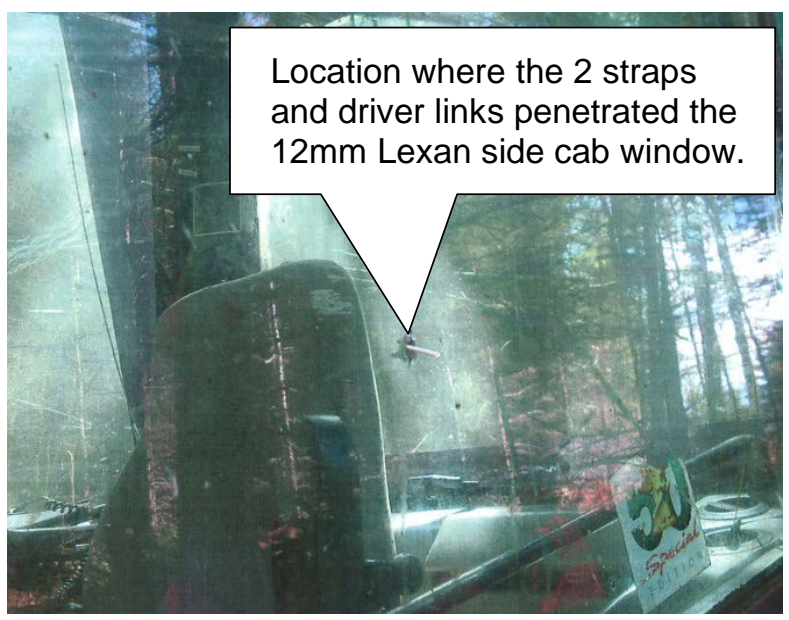

Photo 2: $12 \mathrm{~mm}$ Lexan left side cab window that was penetrated by the two straps and driver link. 
The $762 \mathrm{C}$ cutting head can be used for late thinning, final felling of trees, and as a processor (see photo 3 and figure 2). The operator's manual for the cutting head had no mention of chain shot or how to prevent it. The Oregon Mechanical Timber Harvesting Handbook does warn to never allow anyone to stand in front of a rotating chain, or allow anyone within a risk zone of at least 70 meters/230 feet. It states, "Watch especially the area in line with the saw bar!"

The cutting head was equipped with a chain catcher and chain shot arrestor on the heel of the bar drive to serve as a guard in case the chain breaks, but there were no guards on the tip end of the saw to prevent chain shot. The saw box that holds the saw was equipped with snow holes to prevent snow from building up in the saw area.

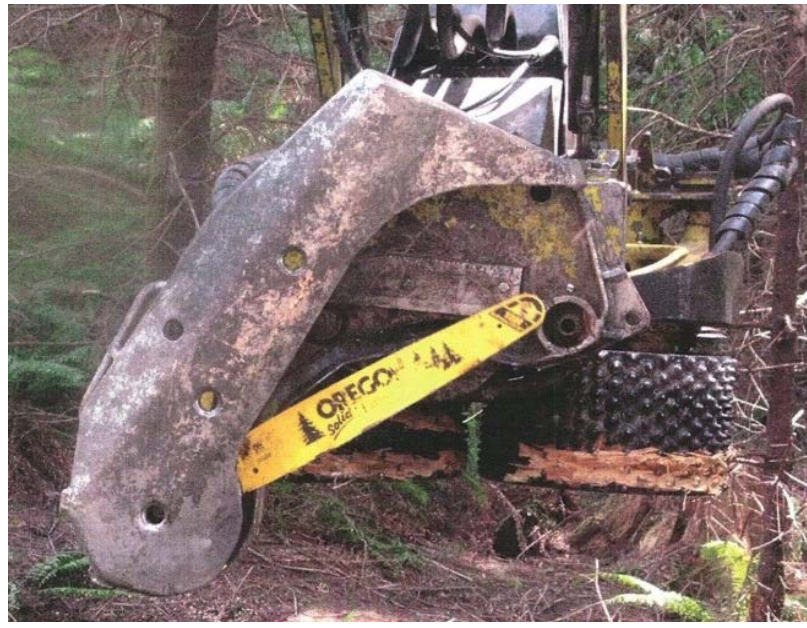

Photo 3: Timberjack 762C cutting head and Oregon roller tip $18 \mathrm{H}$ bar.

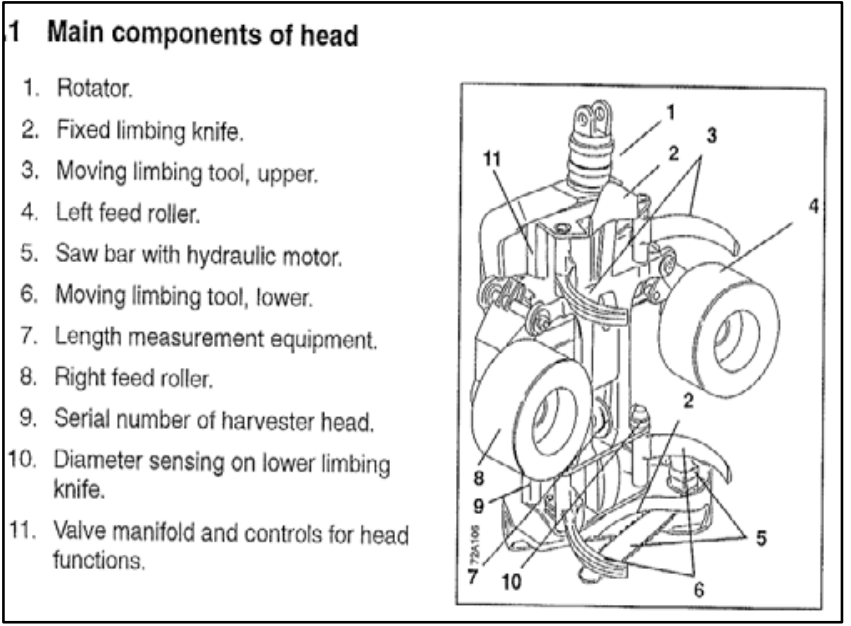

Figure 2: Timberjack $762 \mathrm{C}$ cutting head diagram from operator's manual.

The saw on the cutting head consisted of an Oregon roller tip $18 \mathrm{H}$ saw bar with an 80 gage Carlton chain with a pitch of .404* (see photo 4). According to the employer, the saw moved at up to 8,000 revolutions per minute (RPMs) and was equipped with an auto tensioner. The auto chain tensioner would re-tension the chain after each cut.

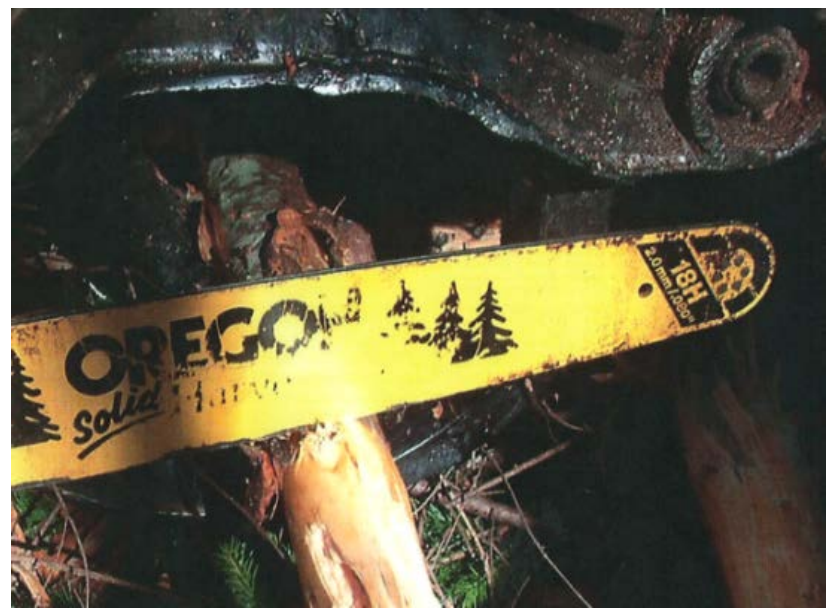

Photo 4: Photo of Oregon $18 \mathrm{H}$ roller tip saw bar involved in the incident.

\footnotetext{
* Gage of a chain refers to the thickness of the drive teeth, while the pitch is the spacing between the drive teeth.
} 


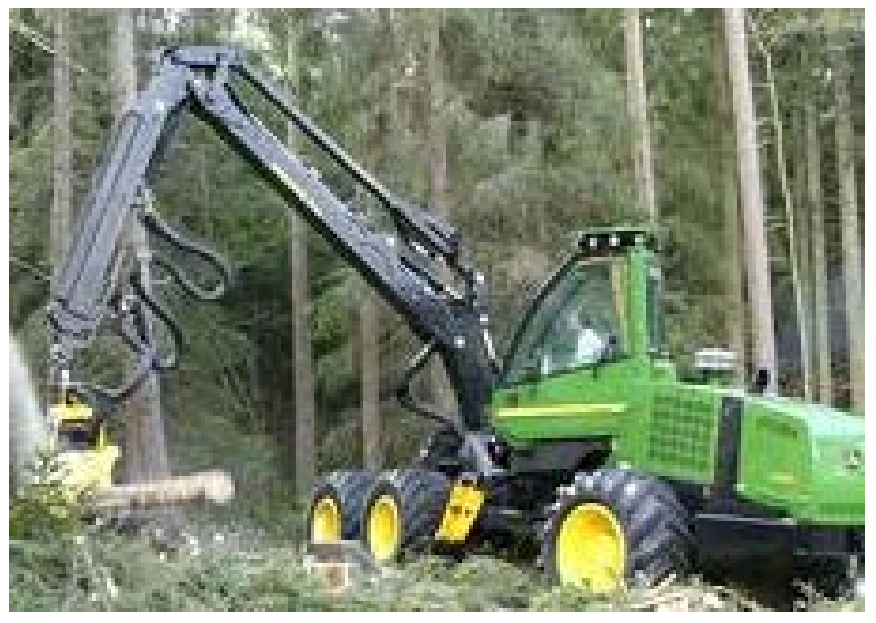

Photo 5: Photo of a harvester in the action of processing a tree with a cutting head. This particular harvester is designed so that the cab and boom with attached cutting head articulate independently. This allows the operator to position the cab so that it is not in line with the cutting bar while processing. (Not the harvester involved in the incident.)

According to the employer, there is conflicting information from manufacturers of harvesters and manufacturers of the saw chains on what is the recommended chain speed. The DOSH inspector determined that the chain speed at the time of the incident was within the manufacturer's recommendations. According to both the employer and the DOSH inspector, the employer properly maintained the cutting head.

\section{Cutting Chain}

The chain on the Oregon $18 \mathrm{H}$ roller tip bar was an 80 gage Carlton chain with a pitch of .404. The chain sections involved in the fatal chain shot were a driver link and 2 strap links (see photos 6 and 7). A drive link is the portion of the chain that fits into the saw's guide bar; the strap link connects the cutter links to the drive links.

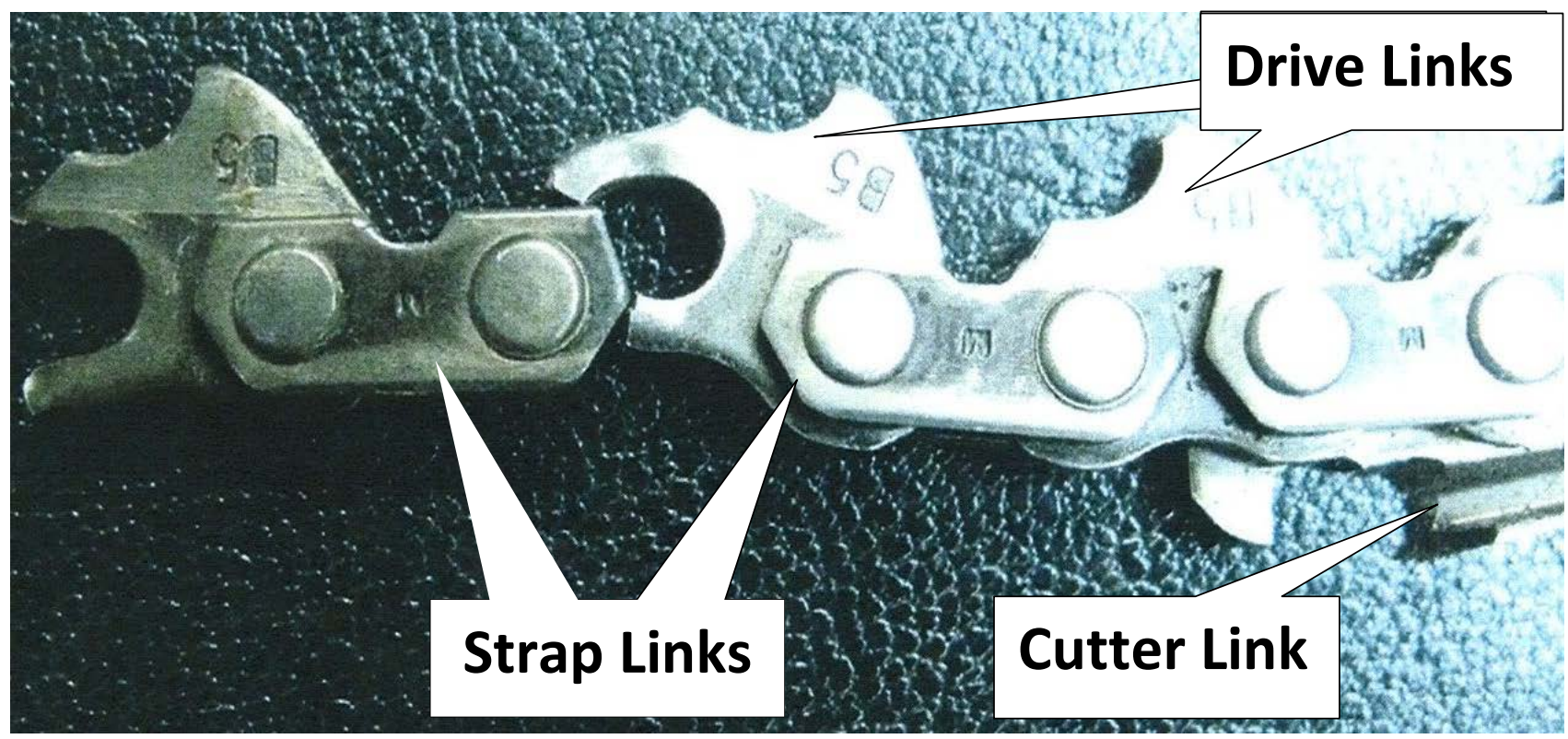

Photo 6: Carlton 80 gage chain with .404 pitch involved in the incident with arrows pointing out different chain links. 
According to the HR manager, the total weight of the two straps and driver link that struck the operator was 102.6 grains (approximately 6.65 grams). According to the chain manufacturer's specifications, the fatal links could have been traveling at speeds up to $310 \mathrm{~m} / \mathrm{sec}$ (approximately 694 miles/hour) when they struck the $12 \mathrm{~mm}$ polycarbonate cab window.

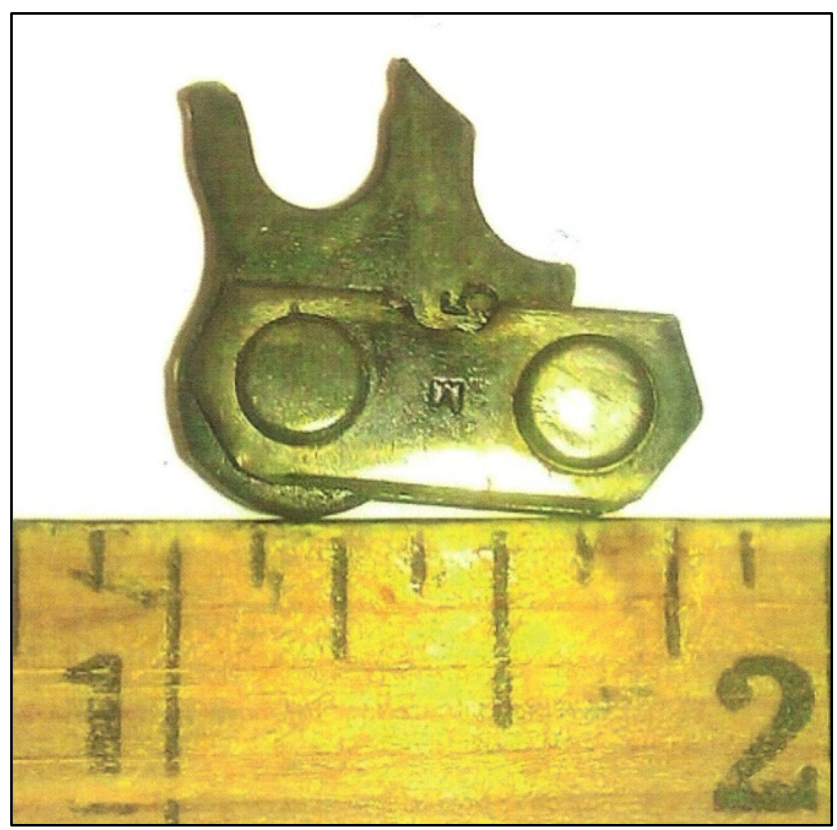

Photo 7: The driver and 2 strap links that struck the operator.

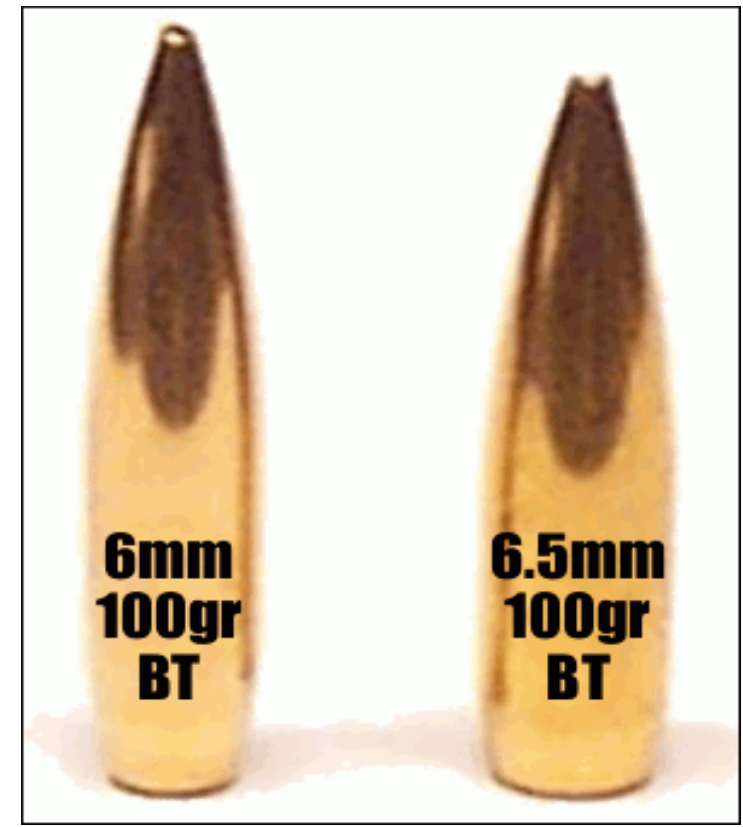

Photo 8: Example of 2 bullets weighing approximately the same weight of the driver and 2 strap links that struck the operator.

\section{INVESTIGATION}

At approximately 9:30 am on August 12,2010 , a crew of two workers, including a forwarder operator and a timber harvester operator, were working to thin an area of trees. The harvester operator, operating a Timberjack 1270B single grip harvester paired with the Timberjack $762 \mathrm{C}$ cutting head, was thinning trees up against a non-fish seasonal stream. The forwarder operator was removing the thinned trees to the road to be hauled off. According to the Washington State Department of Natural Resources (DNR), a non-fish seasonal stream is a stream that does not have surface flow during at least some portion of the year and does not meet the physical criteria of a fish stream. ${ }^{[3]}$ Working near the non-fish seasonal stream limited the space that the timber harvester operator had to work in as some of the trees that needed to be removed would have been located in an equipment limitation zone (ELZ). According to the WA State DNR, an $E L Z$ is a 30 foot wide zone, measured horizontally from the outer edge of the bankfull width or channel migration zone. Machinery can operate within this zone as long as the 
width does not result in sediment delivery to the stream. ${ }^{[4]}$ This would limit the amount of room that the timber harvester operator had to work so that the forwarder operator could remain outside of the ELZ.

Approximately 10 minutes before the incident, the harvester operator contacted the forwarder operator to let him know that he was going to change the chain on the harvester cutting head. After changing the chain the harvester operator continued to thin trees. The last tree the operator cut down was a 6-inch fir tree that was located in front of the harvester.

When the harvester operator was cutting the tree he may have pulled the tree prematurely, as evidence by a 1 inch flap still left on the stump. After cutting the fir tree off the stump, the operator attempted to process the tree with the harvester's cutting head.

It is believed by the employer, that the operator moved the tree to the left side of the cab to ensure that the forwarder would be able to remove the tree without entering the ELZ. This put the tree and the cutting head approximately 10 feet away from the cab of the harvester. With the cutting head in this position the operator was directly in line with the saw.

The cutting head pulled 20 feet of the tree through the feed rollers to cut the tree into the pre-determined length. When the operator hit the saw button to cut the tree, the saw chain rotated and broke. What exactly caused the new chain to break is unknown. Even new chains can be defective.

When the chain broke, a portion of the chain hit the snow hole at the front of the saw. The chain shot occurred before the saw left it's housing to cut the log, as evidenced by the lack of saw marks on the tree it was processing. It is believed by the employer and the DOSH inspector, that this caused the chain shot of the three links in the direction of the cab. Two of the three chain links hit the Lexan $12 \mathrm{~mm}$ window and did not penetrate. The third chain link, consisting of two straps and one driver, penetrated through the left side cab window at approximately a 30 degree angle and hit the operator, cutting his left carotid artery before being embedded in his right shoulder.

The operator made a call on his CB radio to the forwarder operator to call 911 and shutdown the harvester. The forwarder operator arrived on the scene in a couple of minutes, contacted emergency responders, and attempted first aid on the harvester operator. Emergency responder responded on scene in approximately 30-40 minutes. The operator was pronounced dead on the scene. 


\section{CONTRIBUTING FACTORS}

- Ability for piece of chain to penetrate Lexan cab window.

- Cutting head in line with the harvester operator's cab.

- Working in areas with administrative and terrain constrictions (ELZ and non-fish seasonal stream).

\section{CAUSE OF DEATH}

The medical examiner listed the cause of death as acute hemorrhage, exsanguination due to penetrating projectile wound to neck.

\section{RECOMMENDATIONS AND DISCUSSION}

\section{Recommendation 1: Employers should create maintenance and guarding} systems that reduce the chance of chain shot and to protect workers.

\section{Discussion:}

Extensive research by the Forestry Research Institute (FRI) in Sweden found that worn or damaged chains are more likely to break and have an incident of chain shot than chains that are in good condition. ${ }^{[5]}$ Employers should create a system of maintenance that reduces the likelihood of chain breakage. The FRI in Sweden recommends that:

- Chains be inspected for damage, particularly on drive links, before sharpening.

- Chains be replaced at appropriate times.

- Chains be inspected by operators at time of installation.
- Chains be randomly inspected after being sharpened and prior to being installed.

- Operators and workers responsible for chain maintenance effectively communicate.

\section{Post-Incident Remediation}

Since the incident the employer has created both engineering and administrative controls to protect workers from the dangers of chain shot.

\section{Engineering Controls}

The employer has created and attached a tip guard for the cutting saw. The tip guard is intended to direct chain shot or other propellant from the tip of the cutting saw to the ground. The employer also covered the snow holes on the cutting head. Covering the snow holes prevents chain shot from flying out one of the holes. According to the employer, the snow holes are not necessary for the environment that the company works in. 


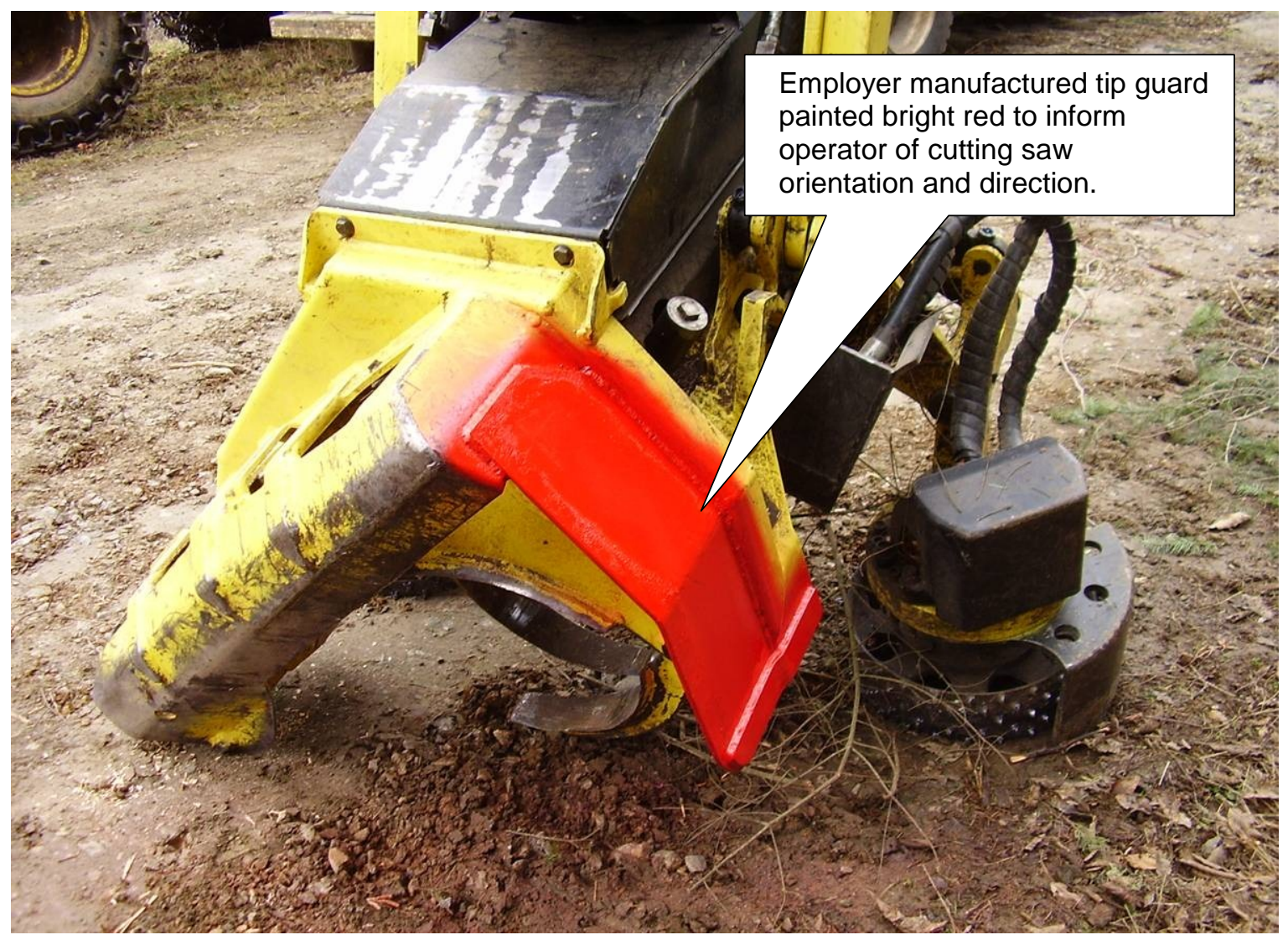

Photo 9: Tip guard manufactured by the employer after the incident. The design of the guard is intended to force any occurrence of chain shot down towards the ground.

The employer did retrofit some of their processor cabs with thicker, more protective, Lexan windows. This was not done for their harvester cabs for two main reasons. First, the harvester front cab window is curved. Thicker aftermarket replacement versions of the curved front window specific to this model harvester are not available. Second, the manufacturer did not support the change. According to the employer, the manufacturer does not approve of upgrading the cab windows due to concerns about the effects on the cab's operator protection structure (OPS).

\section{Administrative / Management Controls}

The employer believes that the best way of preventing similar chain shot incidents is to eliminate chain breakage. In order to accomplish this goal the employer developed a comprehensive program for maintaining chains and trains all equipment operators and chain maintenance personnel on the procedures. 
The initial phase of the employer's plan included replacing all chains, inspecting all machinery, replacing worn parts, and checking all cutting speeds and bar feed force to ensure that they match the manufacturer's recommendations.

After the initial phase the employer developed a comprehensive plan for chain maintenance and trained equipment operators and chain maintenance personnel on it. The plan focuses on inspection, maintenance, and tracking of chains and cutting equipment.

Machinery operators and maintenance personnel now have designated areas to pick-up and drop-off the chains. The chains that are used for processors are put in orange bins with a designated machine number (see photo 10). These orange bins have motor oil in them to pre-lube chains as well as keep the chains clean and help prevent weathering. The employer initially used bar oil, but found that the employees didn't like the "stickiness" of the bar oil and were less likely to follow this procedure. The employer spoke with a chain manufacturer to see if motor oil would be an acceptable replacement. The manufacturer said that motor oil would work just as well as the bar oil for the pre-lube. Bar oil is still required to be used in the processor head during operation. Machinery operators pick-up the numbered orange bin, from underneath the maintenance table, which corresponds with the equipment they will be using in the field. Maintenance personal only put the chains in the bins after they have been cleaned, inspected and serviced.

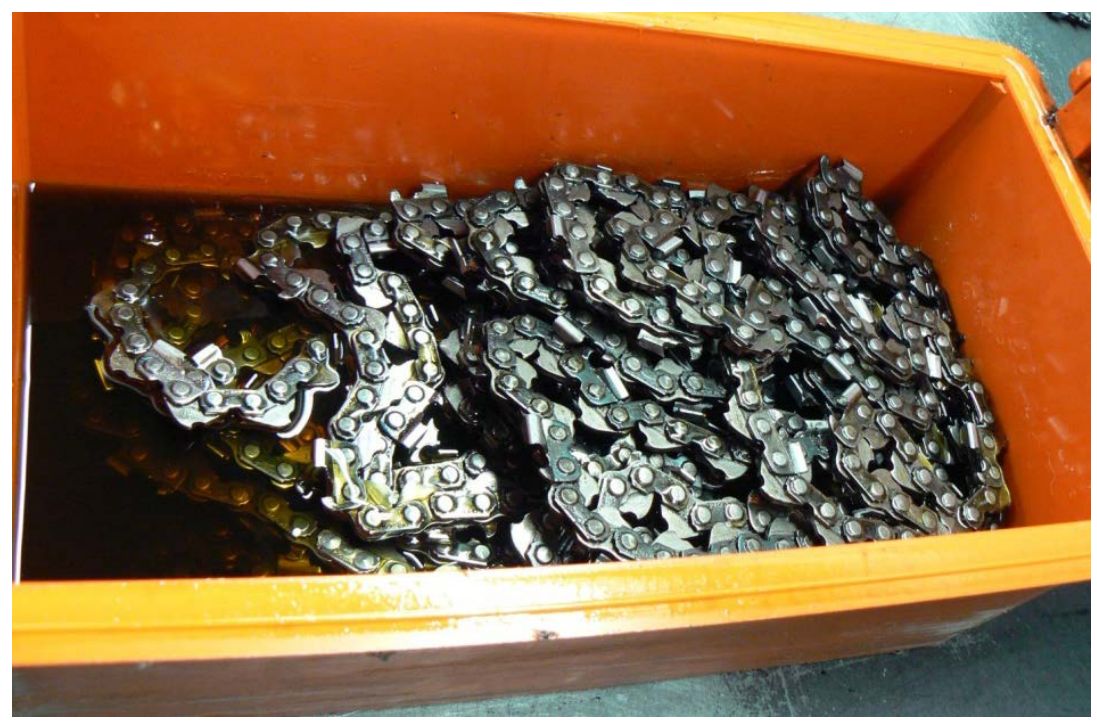

Photo10: Photo showing the inside of the orange bins with motor oil used to pre-lube chains. 
While the machinery operator is on a job they are expected to:

- Store spare chains in motor oil for pre-lube and protection.

- Inspect and replace chains at the end of the shift or as needed after an upset condition. For example, if the chain gets bound while cutting a tree or if the chain becomes really dull.

- Flip and inspect bar once per shift. Clean oil holes and chain groove.

- Inspect sprocket, chain shot guard, chain catcher and lubrication system once per shift.

- Not reuse chains that have been changed.

- When returning from a job, put the used chains on the proper hook on the return chain rack.

When the machinery operator returns from a job the chains are put on the return rack (see photos 11 and 12). The maintenance personnel pick-up, clean, and inspect the chains, discarding worn or damaged chains. The chains that are still in operational condition will be serviced, sharpened, and stored in bins of motor oil before being used again.

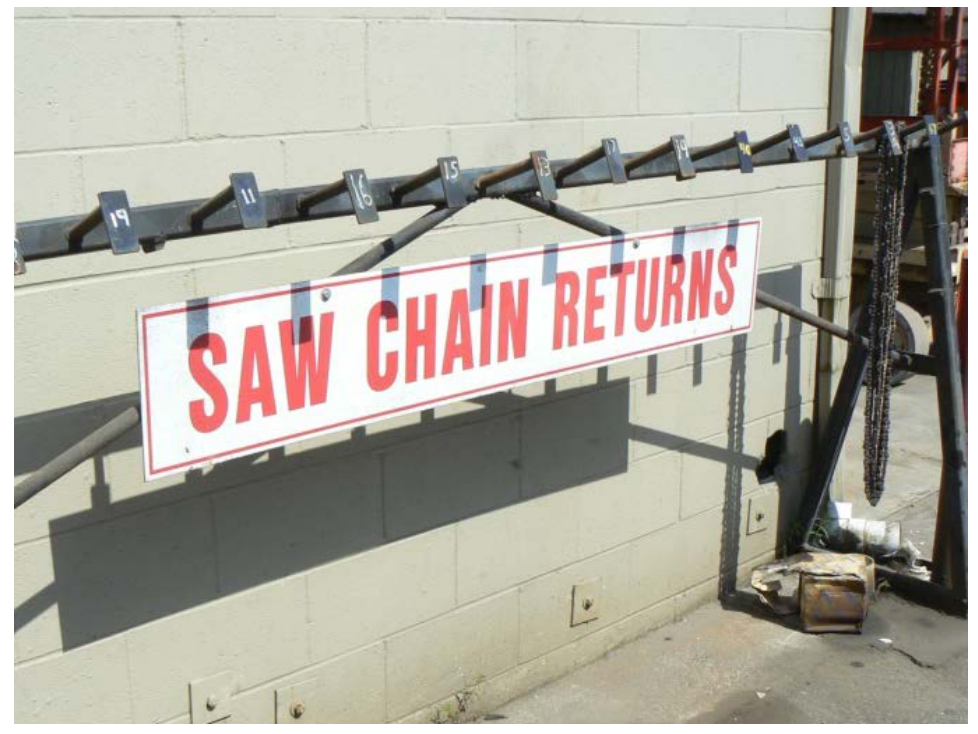

Photo 11: The numbered chains return rack used by equipment operators.

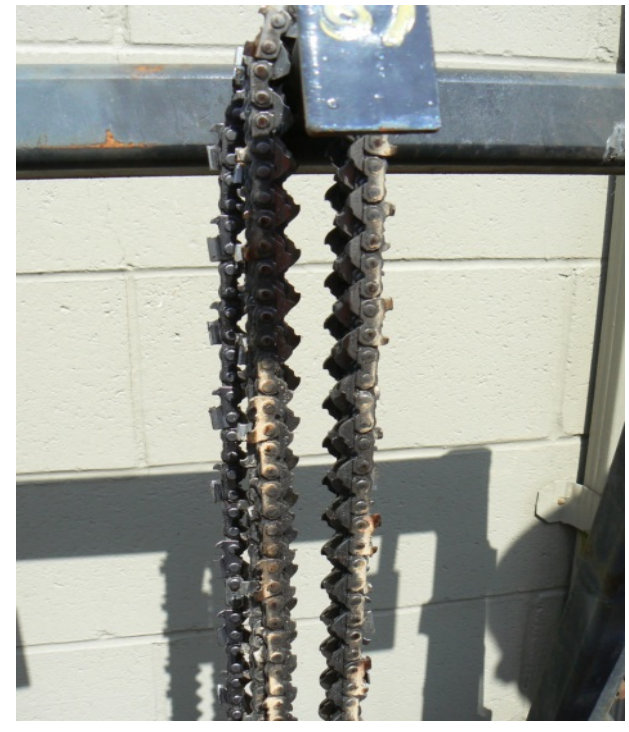

Photo 12: Close-up of chains returned to numbered rack.

Maintenance personnel have an area and tools specifically used for inspecting and maintaining chains. The maintenance staff cleans and inspects chains, checking for structural wear, cracks, and other damage that would make the chain more likely to break. If the chain is still in good condition, maintenance personnel services and sharpens and places the chain back into the appropriate orange bin. 


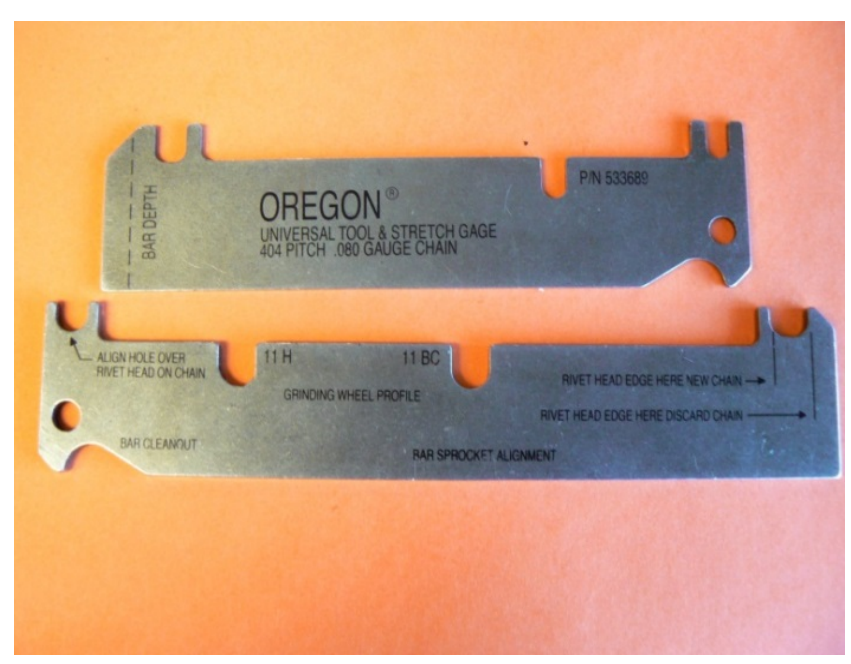

Photo 13: Tools used for inspecting chain stretch and bar depth.

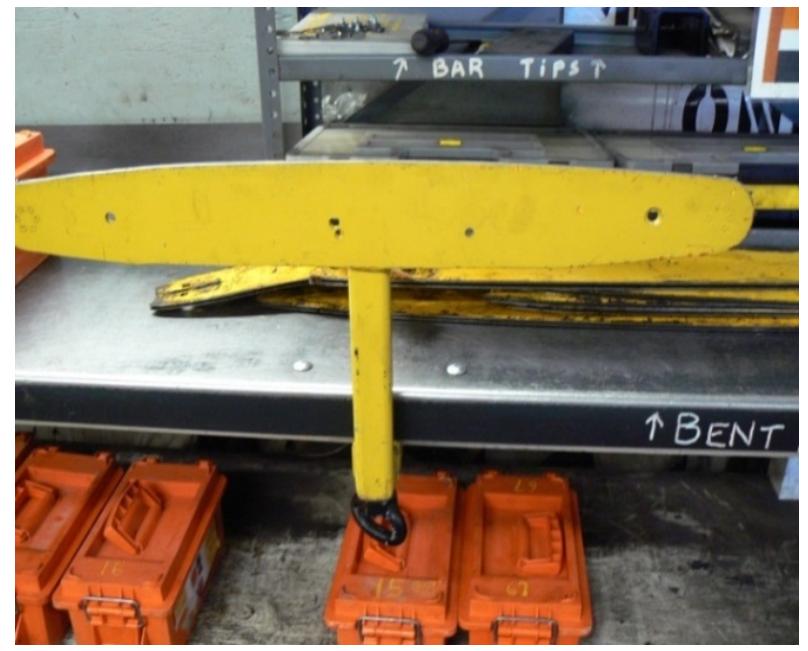

Photo 14: Mounted bar used to inspect and perform maintenance on chains. Underneath the bar is the orange bin pick-up location for machinery operators.

To ensure that the chains go into the correct bin, the employer has two racks in the maintenance area that match the machinery operators' return rack. One rack is located on the walls of the maintenance shop and is used to put the chains that have been returned by operators. The second rack is used to store chains that have gone through the service and maintenance procedures and will be used in the field (see photo 15). This rack has a lock on it to prevent machinery operators from taking the wrong chain into the field. After cleaning, inspecting, and maintenance of chains that can be reused in the field has been completed, the chains are put back into the orange bin or on the chain rack that has the corresponding number of the machine that will use those chains.

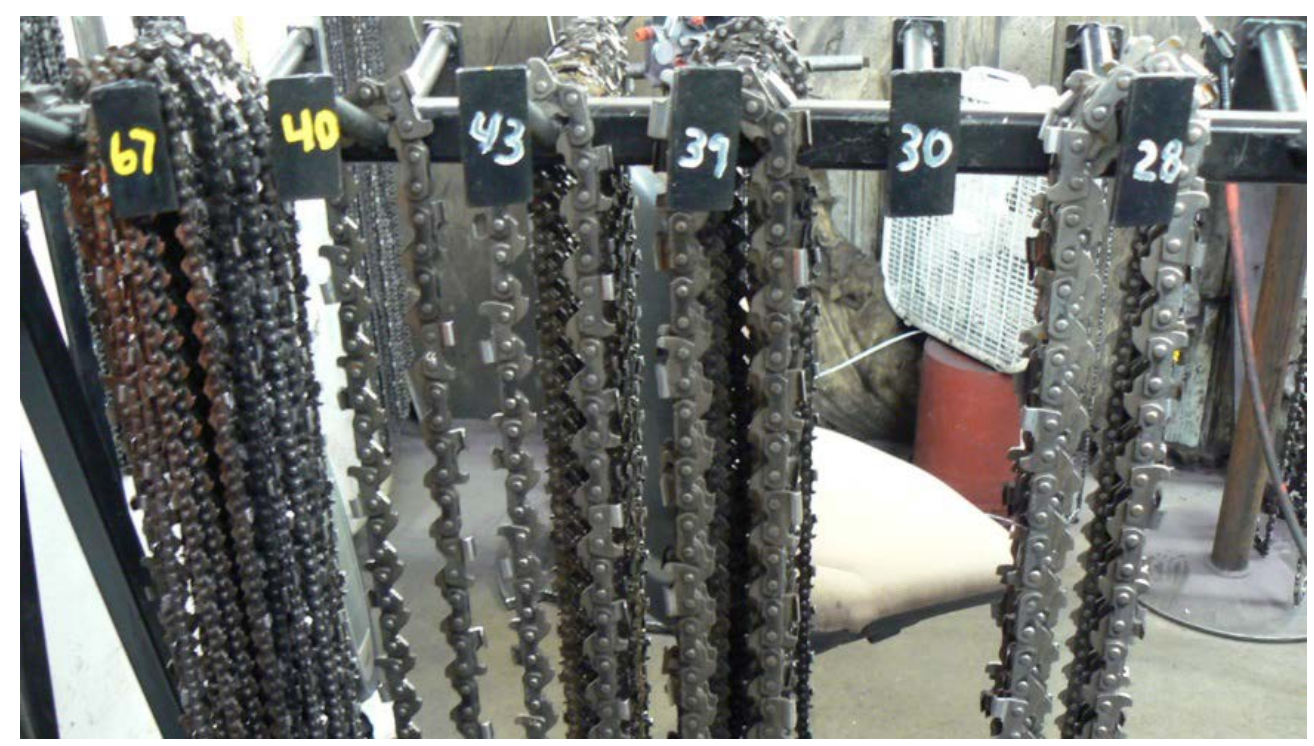

Photo 15: Numbered rack in maintenance shop. Chains on rack have been inspected and are waiting to be put into orange bins with motor oil. Rack is locked to ensure that equipment operators cannot take chains from rack. 
The employer also became more diligent about inspecting and changing out worn parts on a machine's cutting system. Chain shot guards including the chain catcher and chain shot arrestor as well as sprockets need to be routinely inspected and replaced when worn or damaged (see photos 16 and 17). The employer trains equipment operators to inspect their equipment daily while out in the field. Machinery operators are trained to inspect specific parts and how to identify signs of wear or damage.
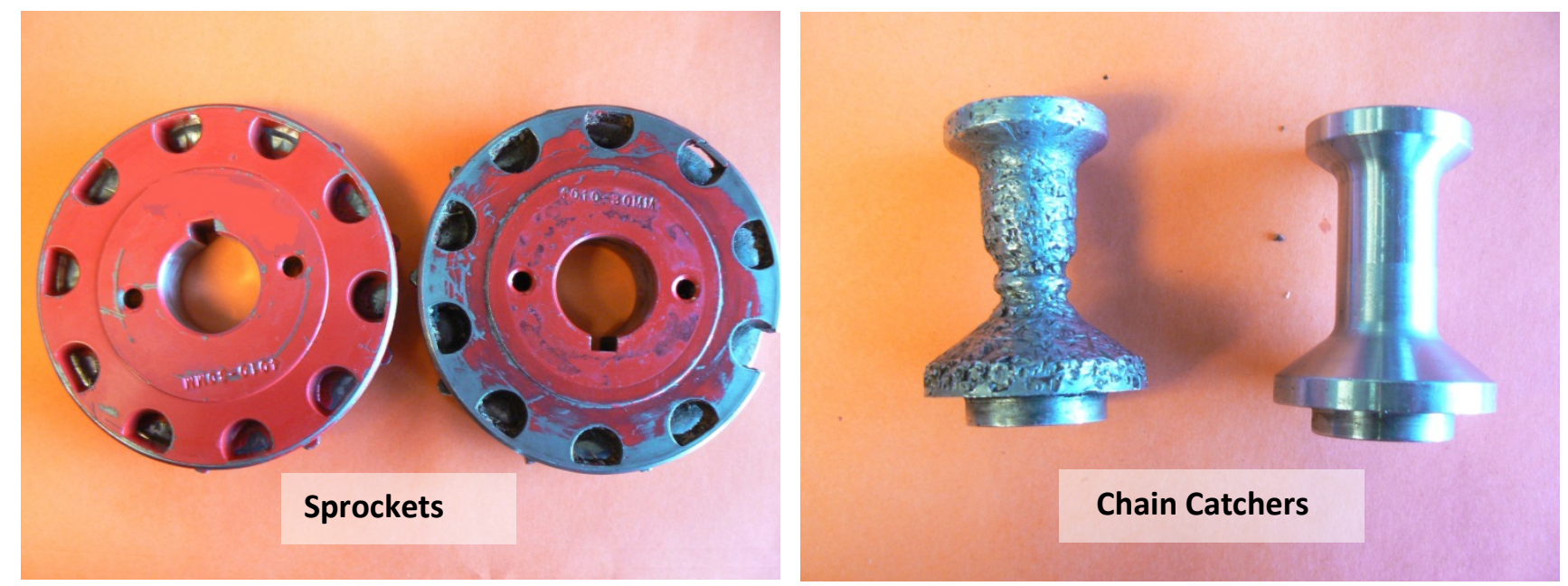

Photo 16 and 17: Used sprockets and chain catcher. The sprocket on the left is worn and was changed at the appropriate time. The sprocket on the right is worn and was run too long. The chain catcher on the left is an example of one that needs to be replaced, while the chain catcher on the right is new.

Since the initial interview the employer's more frequent inspection program has detected a new problem. The problem exists with the heel of the cutter link on the .404 gauge chains. The employer has found that the heel of the cutting link is cracking and failing long before the service limit for stretch on the chain or the limit for wear on the cutting tooth is reached. To compensate for this new issue, the employer replaces the chain after it has been sharpened four or five times, and not when it has passed its stretch service life or the cutting link becomes too worn. The chain maintenance staff is responsible to ensure that chains are discarded at the appropriate time.

The employer estimates that due to the new chain maintenance procedures, they have seen a 50-80 percent reduction on chain breakage.

\section{Recommendation 2: Train all workers who might encounter chain shot on standard operating procedures (SOPs) used for the prevention of chain shot.}

Employers should ensure that all workers and/or contractors that could be exposed to chain shot are properly trained on all chain shot prevention SOPs. Workers that may be 
exposed to chain shot include harvester operators, hand cutters, workers on landings, and truck drivers. The training should include:

- How to identify and prevent chain shot hazards.

- Demonstration of skills needed to perform chain shot prevention SOPs.

- Coaching or disciplinary action for workers failing to use employer's SOPs.

- Documentation of any training, coaching, and or disciplinary action.

- Regular review and or supervision of workers performing SOPs.

\section{Recommendation 3: Harvester operators should whenever possible avoid} processing trees when the processing saw bar is in line with the operator's cab.

\section{Discussion:}

The harvester operator was working in an ELZ and attempted to make it easier for the forwarder operator to pick up the logs. To do this the harvester operator had the cutting head positioned on the left side of the harvester and directly in line with the cab. When the cutting head is in this position, there is a higher risk of chain shot impacting the cab. It is possible that if the cutting head was not in line with the cab, then chain shot may not have struck the harvester operator.

Machinery operators should position the cutting head in a direction that reduces the possibility of chain shot traveling towards the cab. This means they may have to maneuver the equipment into a different position in order to avoid damaging sensitive or restricted areas. If safe to do so, machinery operators could also utilize berms or other obstacles as a barrier from chain shot.

Safe operating practices should be used in addition to other preventive measures such as thicker polycarbonate cab windows and chain guards. A 2008 incident documented by WorkSafeBC, describes chain shot that penetrated $5 / 16$ " inch steel on the side of an operators cab. The chain shot came from a saw that was angled away from the cab and equipped with a chain catcher and guard. This demonstrates that chain shot is unpredictable and cannot be fully controlled by safe operator practices and emphasizes

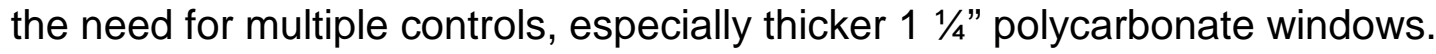

Recommendation 4: Workers should be aware of and in frequent communication with harvester operators regarding their proximity and alignment relative to timber harvesters and the location of safe zones.

\section{Discussion:}

All workers in the vicinity of timber harvesters or other logging machinery equipped with a guide bar and saw are at risk of being struck by chain shot. Chasers, hand cutters, 
and other workers on foot are particularly at high risk. Therefore, workers should always be aware of their distance from and alignment with a guide bar and saw and should use radios and hand signals to frequently communicate this information to operators. This allows operators to know if workers are in or close to high hazard zones so they can position and operate machinery more safely. Currently, the recommended chain shot risk zone distance is 70 meters/230 feet from a rotating chain. However, this should be considered the minimum and whenever possible, workers should be beyond this distance or in safe zones. Workers should also always wear high visibility clothing to help operators be aware of their location.

\section{Recommendation 5: Manufacturers of mechanized logging equipment should ensure that there are multiple safety systems to prevent chain shot penetration of the operator's cab.}

\section{Discussion:}

This has not been the only case of chain shot penetrating $12 \mathrm{~mm}$ polycarbonate cab windows. Harvester operators in the United States, British Columbia, Sweden, and Australia have all reported incidents of chain shot penetrating harvester cab windows.

SMP Svenska Mankinproving AB, a forestry testing facility in Sweden, has carried out extensive research on chain shot, and found that three-ply $19 \mathrm{~mm}$ polycarbonate and $19 \mathrm{~mm}$ polycarbonate/acrylic laminate prevented chain shot from completely penetrating the material. SMP also found that $32 \mathrm{~mm}$ polycarbonate laminate only allowed chain shot to penetrate to a maximum depth of $18 \mathrm{~mm}$. To ensure the safety of harvester operators, manufacturing harvesters with $32 \mathrm{~mm}$ polycarbonate laminate would be most effective. ${ }^{[7]}$ 
Table 2 Three window configurations were tested.

\begin{tabular}{|c|c|l|}
\hline Type & $\begin{array}{c}\text { Total thickness } \\
(\mathbf{m m})\end{array}$ & Description \\
\hline 1 & 19 & Polycarbonate - LEXGARDß RC-750 laminate - three-ply LEXAN@ polycarbonate \\
\hline 2 & 19 & $\begin{array}{l}\text { Polycarbonate / Acrylic - LEXGARD MP750 laminate is a three-ply LEXAN@ } \\
\text { polycarbonate and acrylic laminate }\end{array}$ \\
\hline 3 & 32 & $\begin{array}{l}\text { Polycarbonate - LEXGARDß SP-1250 laminate - four-ply LEXAN@ polycarbonate } \\
\text { laminate }\end{array}$ \\
\hline
\end{tabular}

Table 3 Window test results.

\begin{tabular}{|c|c|l|}
\hline Type & $\begin{array}{c}\text { No. of } \\
\text { tests }\end{array}$ & Observations \\
\hline 1 & 10 & $\begin{array}{l}\text { Projectiles were able to penetrate the material and cause a 5mm deformation on } \\
\text { the rear surface on the window. Refer to Figure 3. }\end{array}$ \\
\hline 2 & 7 & $\begin{array}{l}\text { Projectiles where able to penetrate the outer polycarbonate layer, but were } \\
\text { contained by the acrylic layer. The rear layer of polycarbonate was not } \\
\text { penetrated, however it was partially delaminated. Refer to Figure } 4 .\end{array}$ \\
\hline 3 & 9 & $\begin{array}{l}\text { Projectiles were able to penetrate the material to a maximum depth of } 18 \mathrm{~mm} . \\
\text { Refer to Figure 5. }\end{array}$ \\
\hline
\end{tabular}

Figure 3: Tables 2 and 3 from the SMP Svenska Mankinproving AB Testing of Chain Shot showing that $19 \mathrm{~mm}$ and $32 \mathrm{~mm}$ prevented chain shot from penetrating through the cab window.

Polycarbonate may not be the only option for harvester cab windows. Recent research conducted by the United States Army and the University of Dayton Research in Ohio found that a new type of transparent armor made from aluminum oxynitride and a polymer backing can prevent penetration of a .50-caliber bullet. According to the research, the material is about half the weight of current materials used, usually a polycarbonate and glass combination, in military vehicles. The aluminum material is also expected to retain its clarity for longer than current products used. The estimated cost of aluminum oxynitride, in 2005 , was approximately $\$ 10$ per square inch, but the price could come down with mass production. ${ }^{[6]}$

Due to the cost of newer machines many mechanized logging companies may not be able to afford newer equipment, so retrofitting older equipment with more protective cab windows could reduce the likelihood of an operator being struck by chain shot. Manufacturers of harvesting equipment should work with employers to determine the best method for retrofitting older equipment while maintaining the structural integrity of the harvester and any operator protection structures (OPS).

Manufacturers of cutting heads should develop and provide employers with the options to purchase guards to cover the tip end of the cutting saw. The employer stated that the guard that they have retrofitted has not interfered or negatively impacted their operations. The tip guard has also increased harvester operators' awareness of the saw bar alignment. The HR manager said that many of the operators have stated they didn't realized how often they were in the line of the cutting saw until the tip guard was put on and painted bright red (see photo 9). This visual reminder could help operators 
recognize that they are in line with the saw before they begin processing a log; this would give them a cue to change the angle in which they are processing logs.

Since mechanized logging equipment is used in many different environments, not all employers will need the same features, such as snow holes. Manufacturers of cutting heads should create various options or packages that allow users to tailor the cutting heads to meet the needs of the environment(s) they will be used in.

Timber harvesters are designed so that they are able to be operated in the high risk position where the saw bar is aligned with the operators cab. The Timberjack 1270B harvester in this incident had a rotating boom but a fixed cab that limited the options for positioning during processing. Harvesters with independently rotating cabs and booms provide operators with more options for safe positioning and operation. Manufacturers should further design harvesters to allow for more safe operating options and promote these features to users. 


\section{Appendix A:}

\section{Cutting Chain Life Cycle}

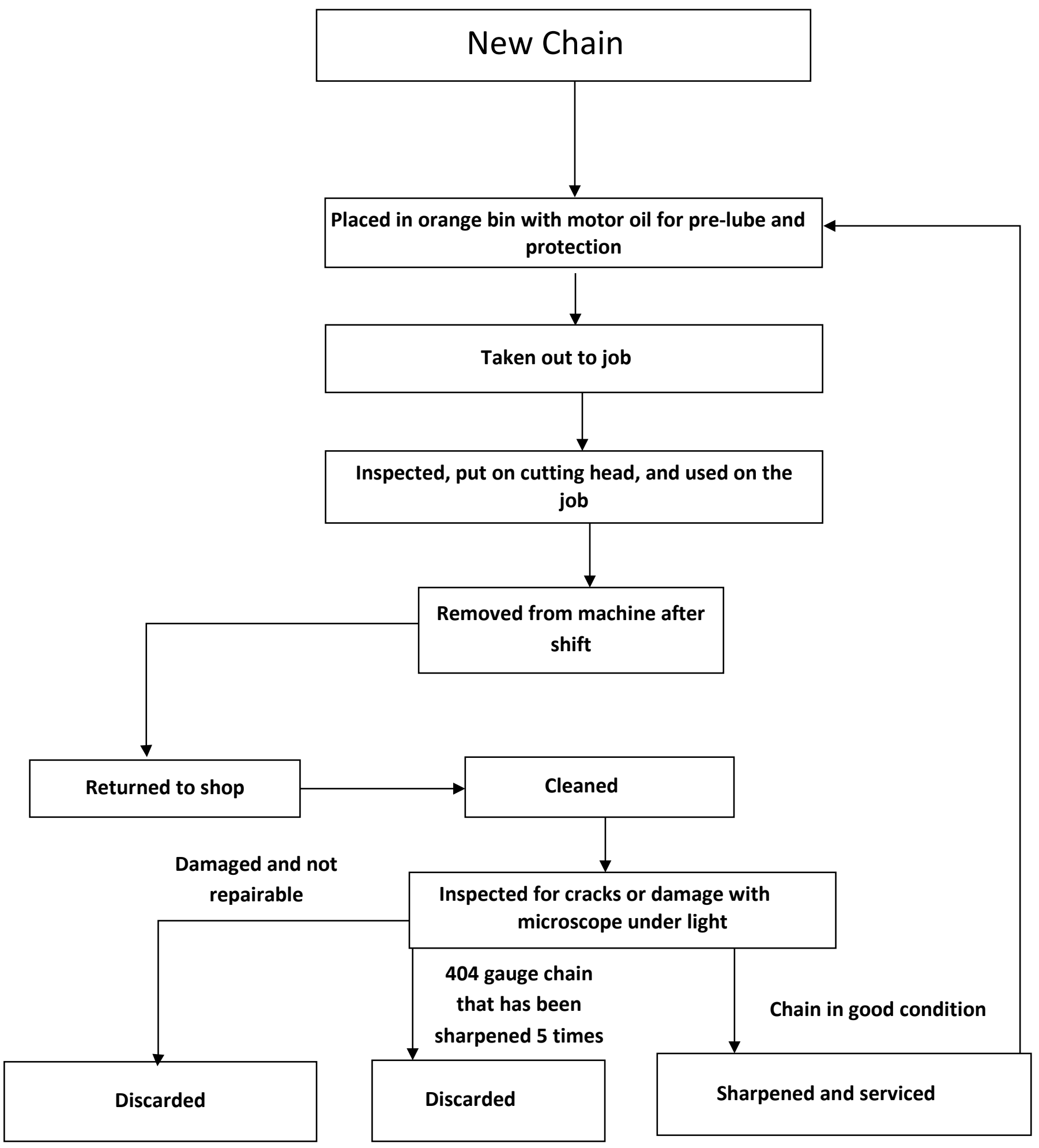




\title{
Appendix B: Example of Training Guidelines (wording in red added after incident)
}

\author{
JOB TRAINING GUIDE --- SINGLE GRIP HARVESTER/FELLER \\ BUNCHER/FORWARDER OPERATOR
}

(Page 1 of 2)

Employee

Trainer

Date

Wear a hard hat when outside the cab and gloves for maintenance work. If called upon to run a chain saw, leg, eye and hearing protection are also required. Footwear must be suitable for the job.

Slips and falls are a major hazard. Keep oil spills and grease cleaned up. Use ladders and grab rails. Don't jump from the machines.

Ensure workers and other machinery are at least two tree lengths away before falling trees.

Keep unauthorized people away from feller bunchers/single grip harvesters (At least two tree lengths) and

forwarders.

Don't work alone. Stay within visual or hearing contact of another worker.

Read and become familiar with the manufacturer's Operator's Manual before operating.

When double cutting oversized trees, leave enough holding wood to support tree while you re-position head.

Before any employee begins maintenance or servicing of equipment where the unexpected energizing, start-up, or release of stored energy could cause injury, the equipment will be shut down, isolated from all potentially hazardous energy and locked or tagged out. SEE LOCKOUT/TAGOUT PRORAM.

Inspect machine and make necessary repairs before operating.

Avoid traveling across steep slopes or operating on slopes that exceed the machine's capability.

Clear combustible debris such as limbs, bark, etc. from the machine. Make sure you have a fully charged fire extinguisher(s) available.

Use warning signs and flaggers or block road if falling timber can reach a road.

For your safety and the safety of others, point out unsafe conditions or acts.

Never allow someone to hitch a ride on any part of the machine.

The minimum operating clearance between energized electrical lines and any part of equipment is 15 feet. Trees along power lines must be directionally fell away from the lines. No trees should be permitted to fall within 15 feet of electrical lines. If a tree does contact a power line, all employees must remain clear of the area until the power company ensures that there is no electrical hazard.

Lower the head to the ground, set the brakes and engage the hydraulic lockout before leaving the machine. When outside your cab near standing timber, watch for widowmakers and hung-up trees.

The following principles should be followed when lifting: squat down, don't bend or twist, keep the feet in a wide base of support, keep the object as close to the body as possible, keep the back in it's normal curve and lift with the legs, remember to lower objects in the same way.

Don't allow anyone behind the cab guard while the truck is being loaded unless the loading operation stops and it is safe to do so.

Maintain solid log decks, and build stable loads.

Do not swing logs near of over anyone.

Filter System: Contamination introduced through dirty hoses, dirty hydraulic oil, dirty buckets or funnels will damage all hydraulic components including pumps, motors and control valves causing severe functional problems. Do Not use dirty hoses, keep system clean and sanitary!

Road Maintenance: Use extreme care and caution when you enter, exit, or travel on any road. When possible use the boom to assist in turning. This helps keep damage to a minimum.

If possible park on flat ground prior to exiting.

In event of equipment failure or fire shut equipment down before exiting vehicle.

(Forwarders \& Harvesters) Engaging "Emergency Stop" on the control panel (Large Red Button), will immediately apply brakes. Engage the E-Stop anytime the motor stops, this will prevent injury and costly machine damage. 


\title{
JOB TRAINING GUIDE --- SINGLE GRIP HARVESTER/FELLER BUNCHER/FORWARDER OPERATOR

\author{
(Page 2 of 2)
}

\begin{abstract}
When refueling or servicing equipment pull pick up to the machine, perform work, then pull pick away before operating machine. NEVER PULL MACHINE AWAY FROM PICKUP OR SERVICE TRUCK.

CHAIN SHOT- Chain shot is the high velocity separation and ejection of cutting chain from the end of a broken saw chain in mechanized timber harvesting. Chain shot exposes both machine operators and bystanders to a risk of serious injury or death.

Unauthorized personnel and / or bystanders must be at least 230 feet away from working processors to protect from chain shot.

Minimize operating the saw bar in the direction of the cab.
\end{abstract}

Revised 10/4/12

Page 23 


\section{ACKNOWLEDGEMENTS:}

This report was reviewed by stakeholders from labor and business communities and various Washington State and federal worker safety agencies. Though we are unable to acknowledge specific individuals for their contributions to this report, we would like to recognize the following for their help and support of the FACE mission and objectives:

- $\quad$ The Employer's representatives involved in the incident

- $\quad$ Division of Occupational Safety and Health (DOSH)

- $\quad$ Federal FACE Program Management (NIOSH)

- $\quad$ Safety \& Health Assessment \& Research for Prevention (SHARP)

\section{REFERENCES:}

1. Oregon. Chain Shot. 1/4/2012; Available from: www.oregonproducts.com/harvester/service/chain_shot.htm.

2. Washington State Department of Labor and Industries., Classification for Washington Workers' Compensation Insurance, in 296-17A-5005 Washington Administrative Code, Washington State Department of Labor and Industries, Editor 2010. http://apps.leg.wa.gov/wac/default.aspx?cite=296-17A-5005

3. Washington State Department of Natural Resources. Forest Practice Water Typing. 1/4/2012; Available from: www.dnr.wa.gov/BusinessPermits/Topics/ForestPracticesApplications/Pages/fp watertyping.aspx.

4. Washington State Department of Natural Resources. Forest Practice Board Manual, Forest Practice Board, Editor 2010, Washington State Department of Natural Resources Olympia, WA. p. 1-16.

5. Hallonborg, U., Closer inspection of chains can reduce danger of chain shot, in Results 2002, The Forestry Research Institute of Sweden: Uppsala, Sweden.

6. Live Science Staff. Military: New Aluminum Windows Stop .50-Calibur Bullet. 2005 [cited 2013 March 27, 2013]; Available from: www.livescience.com/420military-aluminum-windows-stop-50-caliber-bullet.html.

7. Chain Shot Primer 10/2012. Available from https://woodbusiness.annexweb.com/harvesting/chain-shot-primer 


\section{INVESTIGATOR INFORMATION:}

Todd Schoonover has a PhD in Industrial Hygiene from the University of Illinois at Chicago. He is a Certified Industrial Hygienist $(\mathrm{CIH})$ and Certified Safety Professional (CSP). Todd is currently the Principal Investigator for the WA FACE program.

Eric Jalonen has a Master's in Public Health from East Carolina University. He is a Research Investigator with the WA FACE program.

Randy Clark has a BA from The Evergreen State College. He is a Research Analyst with the WA FACE program.

\section{Washington State FACE Program Information}

The Washington State Fatality Assessment and Control (WA FACE) program is one of many workplace health and safety programs administered by the Washington State Department of Labor \& Industries' Safety \& Health \& Research for Prevention (SHARP) program. It is a research program designed to identify and study fatal occupational injuries. Under a cooperative agreement with the National Institute for Occupational Safety and Health (NIOSH grant\# 5 U60 OH008487-09), WA FACE collects information on occupational fatalities in WA State and targets specific types of fatalities for evaluation. WA FACE investigators evaluate information from multiple sources. Findings are summarized in narrative reports that include recommendations for preventing similar events in the future. These recommendations are distributed to employers, workers, and other organizations interested in promoting workplace safety. NIOSH-funded, statebased FACE programs include: California, lowa, Kentucky, Massachusetts, Michigan, New Jersey, New York, Oregon, and Washington. WA FACE does not determine fault or legal liability associated with a fatal incident. Names of employers, victims and/or witnesses are not included in written investigative reports or other databases to protect the confidentiality of those who voluntarily participate in the program.

Additional information regarding the WA FACE program can be obtained from:

Washington State FACE Program

www.Ini.wa.gov/Safety/Research/FACE/default.asp

PO Box 44330

Olympia, WA 98504-4330

1-888-667-4277 